\title{
A semi-systematic literature review on supplier selection in construction projects
}

\author{
Gul Polat*iD \\ Istanbul Technical University, Department of Civil Engineering, Istanbul, Turkey
}

\begin{abstract}
It is commonly acknowledged that the competition is very fierce in the construction industry. The business continuity of contractors is mainly dependent on the success -of the completed projects. The success criteria of construction projects can be described as finishing the construction work on time, within the budget and meeting the desired quality level. Since the cost of materials constitutes nearly $40 \%$ of the overall project budget, delivery of the right amount of materials on the right time and with the desired quality is crucial for the overall project performance. In this context, selecting the right supplier is one of the most important decisions in the construction management field. Therefore, supplier selection has attracted considerable attention in construction. The previous studies that deal with the supplier selection problem in construction projects can be categorized into two main groups, which are; 1) the studies that identify either the supplier selection criteria or their importance levels, and 2) the studies propose various multi-criteria-decision-making (MCDM) techniques for solving the supplier selection problem. All these studies have substantially contributed to the construction supply chain management body of knowledge. However, there were no studies that simultaneously investigated how the studies, which focus on the supplier selection problem, evolved in terms of both the considered supplier selection criteria and the employed MCDM techniques over the years. In order to fulfill this knowledge gap, this study reviews the previous studies on supplier selection in construction projects from this perspective. It was found that although cost, time and quality have been considered to be the primary supplier selection criteria, the remaining criteria are specific to project/company/case in question and they are specified by the experts, who are responsible for the selection process. Also, in recent studies, the MCDM methods extended with fuzzy numbers, grey numbers, rough numbers, etc. have been preferred in order to cope with the uncertainty and vagueness in the preferences of the decision makers.
\end{abstract}

\section{Keywords}

Supply chain management; Supplier; Supplier selection; Criteria; Multi-attribute-decision making; Literature review

Received: 20 October 2021; Accepted: 24 December 2021

ISSN: 2630-5771 (online) (C) 2021 Golden Light Publishing All rights reserved.

\section{Introduction}

The construction industry plays a significant role in the growth of national economies and it substantially contributes to employment. As a result of the importance of the construction industry, numerous companies do business in this industry and thereby the competition becomes very fierce in the market. It is commonly acknowledged that material related activities constitute more than half of the total project cost and have tremendous effects

\footnotetext{
* Corresponding author

Email: polatgu@itu.edu.tr
} 
on the project schedule in construction projects [13]. There are a great number of suppliers in the market, and each supplier may promise different advantages such as lower price, superior quality, more convenient and effective service, etc. [4]. Production, transport, storage, or purchase is being highly-affected by the selected supplier and working with a wrong supplier infamies company's reputation and competitive position in the market [5].

Construction suppliers are mainly responsible for delivering the requested amount of materials on the right time, with the desired quality, and within the estimated budget. Any problem experienced in the material delivery process such as delivering wrong amount of material, delivering materials that do not meet quality requirements, delivering materials later than needed, etc., may result in poor project performance [6]. Therefore, selecting the right supplier is critical for construction contractors. Construction supply chain management (SCM) encompasses controlling, monitoring, and executing the supply process from raw material to end-user delivery. It starts from the urgent needs of the clients, considers the general contractor as the leading enterprise, connects all participants such as subcontractors, suppliers and clients by means of managing information, material and capital flows starting from bidding to post-construction phase [7].

Since construction projects are complex and require the involvement of several parties and multiple material/systems, construction companies need to decide on not only the desired material/systems but also their suppliers. It is a fact that consideration of project participants is one of the most vital processes that leading to the success of the projects. Suppliers possess the paramount importance to shape a building because of their strategic role on achieving project aims and protecting competitiveness levels of companies. In order to finish the desired project with success, choosing the right supplier is most of the time the key aspect. In this context, an efficient construction SCM may assist project stakeholders in lowering total project costs, shortening project durations, improving flexibility and quality, increasing the reliability of work schedules, improving the competitiveness of the enterprises, etc. [8].

Supplier selection is a well-studied topic in the construction supply chain literature. Therefore, the problem of supplier selection has attracted considerable attention in construction, like other industries. Previously, delivering the requested amount of materials according to schedule, budget and quality constraints were defined as the main responsibility of the suppliers in construction projects [6]. However, supplier definitions have been overhauled dramatically as well as supply chain management practices lately. Ho et al. [9] stated that the decision of sourcing is being made according to the performance history rather than the price nowadays. In order achieve higher performance; contractors need to enhance teamwork and collaboration among project participants while selecting the appropriate systems according to the intended specifications and tasks.

In the construction management literature, numerous studies have dealt with the supplier selection problem since the 1960's. These studies can be categorized into two main groups; 1) the studies aiming to identify the supplier selection criteria and their importance levels, and 2) the studies aiming to propose MCDM techniques for selecting the right supplier. In addition to these studies, only a few studies reviewed the literature on supplier selection in the construction industry (e.g., [10]). It should be noted that many studies present an extensive review of the literature on other aspects of the construction supply chains such as partnering relationships [11], supplier-contractor collaboration [12], risk factors affecting the implementation of SCM [13], etc. However, there were no studies that simultaneously investigated how the studies, which focus on the supplier selection problem, evolved in terms of both the considered supplier selection criteria and the employed MCDM techniques over the years. This was a research gap and this study aims to fulfill this knowledge gap. This study reviews the previous studies on supplier selection in construction projects from this perspective in order to assist 
construction participants in improving their supplier selection processes and creating an agenda for further research.

\section{Research methodology}

Different types of review methodologies, namely systematic, semi-systematic, integrative, etc., can be employed depending on the purpose and the quality of execution. In the case that reviewing every article that may be relevant to the topic in question is impossible, a semi-systematic literature review can be a good approach. A semi-systematic review aims to investigate how research on a selected topic has evolved over time [14]. Since this study aims to investigate how the supplier selection studies conducted in the construction industry progressed over the years in terms of the considered supplier selection criteria and the employed multiattribute-decision-making techniques, a semisystematic literature review was found to be appropriate.

The widely used search engines, i.e., Scopus, ScienceDirect, and Web of Science (ISI), were selected to retrieve the relevant studies. The keywords such as "supplier", "supplier selection", "supplier selection criteria", "construction industry", "construction projects", and "decisionmaking" were searched. Conference proceedings and the journal articles that deal with supplier selection in the manufacturing industry were excluded and only journal articles that focus on supplier selection in the construction industry were analyzed. Then, the abstracts of the retrieved studies were analyzed with their relevance to the research topic. The full texts of the studies, which include both the supplier selection criteria and the decision-making technique for supplier selection, were reviewed in detail. The reviewed studies were reported in chronological order in order to identify the changes in the supplier selection criteria and multi-attribute-decision-making techniques over time.

The methodical guidelines used in this study is presented in Table 1, and the list of the reviewed sources within the scope of this study and their frequencies are demonstrated in Table 2.

The publication years of the reviewed sources are presented in Fig. 1.

Table 1. Methodical guidelines used in this study

\begin{tabular}{|c|c|c|c|c|}
\hline Sources & Keywords & Constraints & Extracted data & Reporting \\
\hline $\begin{array}{ll}\text { - } & \text { Scopus } \\
\text { - } & \text { ScienceDirect } \\
\text { - } & \text { Web of } \\
& \text { Science }\end{array}$ & $\begin{array}{l}\text { "supplier", "supplier } \\
\text { selection", "supplier } \\
\text { selection criteria", } \\
\text { "construction industry", } \\
\text { "construction projects", } \\
\text { "decision-making" }\end{array}$ & $\begin{array}{l}\text { Only journal } \\
\text { articles that focus } \\
\text { on supplier } \\
\text { selection in the } \\
\text { construction } \\
\text { industry were } \\
\text { analyzed }\end{array}$ & $\begin{array}{l}\text { - Supplier selection } \\
\text { criteria }\end{array}$ & $\begin{array}{l}\text { The reviewed } \\
\text { studies were } \\
\text { reported in } \\
\text { chronological } \\
\text { order }\end{array}$ \\
\hline
\end{tabular}

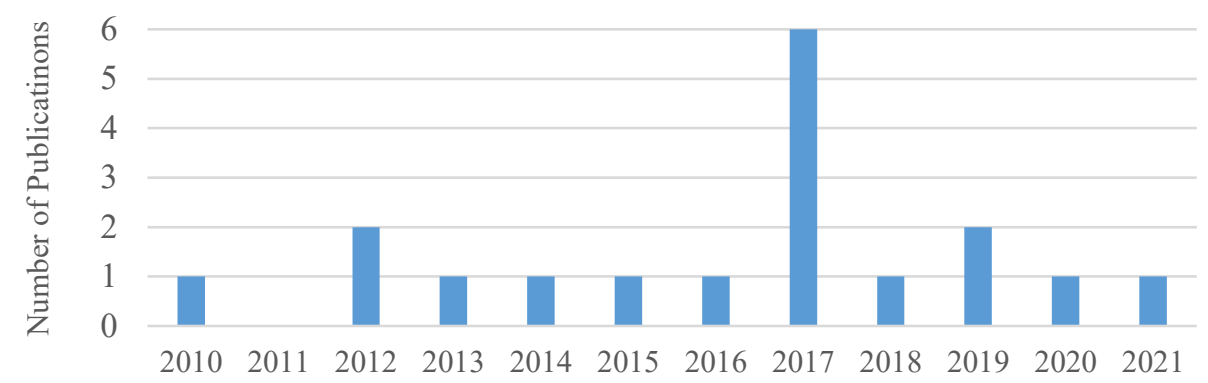

Publication Year

Fig. 1. Publications per year 
Table 2. The list of sources in which the studies reviewed and their frequency

\begin{tabular}{lcc}
\hline Source of the studies reviewed & Frequency & Percentage $(\%)$ \\
\hline Automation in Construction & 3 & $16.67 \%$ \\
Procedia Engineering & 3 & $16.67 \%$ \\
Journal of Civil Engineering and Management & 2 & $11.11 \%$ \\
Technological and Economic Development of Economy & 1 & $5.55 \%$ \\
KSCE Journal of Civil Engineering & 1 & $5.55 \%$ \\
Journal of Construction Engineering and Management & 1 & $5.55 \%$ \\
Sustainability & 1 & $5.55 \%$ \\
Symmetry & 1 & $5.55 \%$ \\
Production Planning \& Control & 1 & $5.55 \%$ \\
Buildings & 1 & $5.55 \%$ \\
International Journal of Strategic Property Management & 1 & $5.55 \%$ \\
Journal of Infrastructure Systems & 1 & $5.55 \%$ \\
International Journal of Production Research & 18 & $5.55 \%$ \\
\hline
\end{tabular}

\section{Previous studies on supplier selection in construction projects}

In literature, supplier selection studies in the construction industry can be grouped as; 1) researches that aim to identify and/or rank the supplier selection criteria, and 2) the researches that introduce methodologies, techniques and tools for selecting the most appropriate supplier selection. The most relevant studies conducted in the period between 2010 and 2021 will be summarized below. It should be noted that green supplier selection or sustainable supplier selection topics are not within the scope of this study.

Lam et al. [15] proposed fuzzy principal component analysis (PCA) for solving the material supplier selection problem. In their study, they used the triangular fuzzy numbers in order to quantify the decision makers' subjective judgments, employed PCA in order to aggregate the supplier selection criteria, and combined the linear score of PCA to rank the alternative suppliers. They considered 7 main criteria, namely cost, quality, service, buyer-supplier relationship, assurance of supply, payment terms, and past performance, and 2 sub-criteria under cost (i.e., total cost and price stability), 2 sub-criteria under quality (i.e., failures prevention and appearance and functions), 3 subcriteria under service (i.e., on time delivery, technical assistance \& support, cooperation \& communication), 3 sub-criteria under assurance of supply (i.e., capability, reliability, and flexibility), and 2 sub-criteria under past performance (i.e., past record and reputation) in their proposed model. They applied the proposed model to one of the largest property developers in Mainland China and concluded that the proposed model can handle both the quantitative and qualitative data at the same time, and it is a user-friendly tool for supplier selection because of the availability of the software, i.e., SPSS and Microsoft Excel.

Zolfani et al. [16] proposed a hybrid MCDM model, which integrates Analytic Hierarchical Process (AHP) and Complex Proportional Assessment of alternatives to Grey relations (COPRAS-G method), for solving the supplier selection problem. In their study, 8 supplier selection criteria, namely cost, quality, distance, delivery, reliability, reputation, technology level, compatibility, and development ability, were taken into account. AHP was used for calculating the weights of the supplier selection criteria and COPRAS-G was used for ranking the supplier 
alternatives. They applied the proposed model to a construction company and verified the functional ability of the proposed model.

Azambuja and O'Brien [17] developed a decision support system, which integrates historical data, market assessment, and bid information, for selecting engineered equipment suppliers in the early stages of capital project using the Aspiration Interactive Method (AIM) to analyze the information. AIM enables decision makers to understand the tradeoffs among different supplier selection criteria. In this study, the supplier selection has three phases, which include: imputing the supplier selection criteria, shortlisting of supplier alternatives, and ranking the shortlisted suppliers based on automatically computed criteria weights using AIM. They applied the developed decision support system to two equipment selection cases (i.e., heaters and compressors), and identified 6 supplier selection criteria, namely duration, material cost, transportation cost, on-time fabrication, on-time shipment, and shop load utilization. The applicability of the developed decision support system was validated through interviews with the decision makers working in the companies in question.

Eshtehardian et al. [18] proposed the use of AHP and Analytic Network Process (ANP) methods for solving the supplier selection problem in construction and civil engineering companies. They identified 5 supplier selection criteria, namely accordance with order, same quality, possibility of rapid delivery, on time delivery, and low number of defective parts. They applied the AHP and ANP methods to select a construction materials supplier for a Iranian construction company. They recommended the use of ANP method if the internal relations between criteria should be taken into account and the use AHP method if there a great number of comparisons and high accuracy is not needed.

Safa et al. [19] developed an integrated construction materials management (ICMM) model, which is based on the main activities associated with the procurement of materials: (1) processing and administration related to purchase requisitions, (2) purchase orders, (3) internal supply requests, (4) shipping, (5) expediting of materials, and (6) supplier selection. They used the TOPSIS (Technique for Order Preference by Similarity to Ideal Solution) method for ranking the alternative suppliers, and applied the proposed model to an industrial project and identified price, lead-time, cash rebate, and supplier performance as projectspecific supplier selection criteria. The conclusion of their study was that the proposed model could successfully be used for selecting the most appropriate supplier.

Polat and Eray [6] proposed an integrated approach that aims to assist construction companies in solving the supplier selection problem in their projects. In the proposed approach, the AHP method was used to find the weights of the supplier selection criteria and the Evidential Reasoning (ER) method was used to rank the supplier alternatives. They applied the proposed approach to a problem of selecting the rail supplier for an intercity railway project in Saudi Arabia. In their study, they identified 8 main supplier selection criteria, namely quality of the product, delivery time, relationship with the supplier, unit price of the product, flexibility in payment conditions, and communication with the supplier, production capacity, and technical competence of the supplier. The applicability of the proposed approach was validated through interviews with the decision makers.

Plebankiewicz and Kubek [20] identified the building materials supplier selection criteria, and proposed the use of AHP and fuzzy AHP for solving supplier selection problem. They applied AHP and fuzzy AHP methods to a problem of selecting the supplier of heaters for a large construction project. They identified 10 building materials supplier selection criteria, namely tender price, payment conditions, cost within a life cycle, quality of materials, original or substitute, supplier's reputation, completion deadline, delivery conditions, guarantee period, and technical expertise. They concluded that the MCDM method chosen for the supplier selection considerably affects the solution and real life problems require 
knowledge from qualified decision makers to determine the selection criteria and/or to assign right weight to each of them.

Cengiz et al. [3] utilized Analytic Network Process (ANP) for solving the supplier selection problem for wall, cladding and roofing construction materials. They identified 10 main criteria, namely, cost, quality, delivery, payment method, geographical location, supplier profile, buyersupplier relations, ecological characteristics, supplier capacity, and technical acceptable materials, and 3 sub-criteria under delivery (i.e., length of term, delivery speed, type of delivery), 3 sub-criteria under payment method (i.e., possibility of payment by installments, possibility of payment by barter, refund possibilities), 3 sub-criteria under supplier profile (i.e., past performance, finance, certificates and references), 3 sub-criteria under ecological characteristics (i.e., environmental awareness, ecological material possibility and diversity, environment-oriented certification), and 5 sub-criteria under supplier capacity (i.e., product range, production/storage capacity, technical competence, technology, post purchase service). They conducted a questionnaire survey among 80 construction professionals in order to determine the importance levels and weights of the criteria and sub-criteria, and tested the applicability of the proposed model through an illustrative example.

Wang et al. [21] proposed an integrated methodology for selecting the most appropriate supplier, which include applying AHP to determine the weights of the supplier selection criteria, using the weights of the qualitative and qualitative criteria to calculate the grey weighted correlation coefficient; and using grey relational analysis (GRA) to analyze the qualitative and quantitative data regarding the evaluation of performances of the alternative suppliers and to rank the alternative suppliers. They took into account 5 main criteria, namely primary performance factors, flexibility, enterprise capacity, research \& development, and green abilities, and 3 sub-criteria under primary performance factors (i.e., product quality, commodity price and cost, delivery and service), 3 sub-criteria under flexibility (i.e., time flexibility, product flexibility, quantity flexibility), 6 subcriteria under enterprise capacity (i.e., management level, risk reduction and responsiveness, reputation and prestige, political and legal environment, service distance, the level of informatization), 2 sub-criteria under research \& development (i.e., new product development, new technology development), and 3 sub-criteria under green abilities (i.e., energy saving and environmental protection, eco-design, pollution). They simulated a two-story complex construction project in order to illustrate how the proposed framework can be used.

Polat et al. [22] proposed an integrated approach, which employs fuzzy AHP and fuzzy TOPSIS together, for solving the supplier selection problem. In their study, they used fuzzy AHP to calculate the weights of the criteria and employed the fuzzy TOPSIS method to rank the alternative suppliers, and applied the proposed model to a rail supplier selection problem in a real life project. They used the triangular fuzzy numbers in order to quantify the decision makers' subjective judgments and identified quality of the product, lead time, delivery performance, total cost of the product, payment conditions, communication with the supplier, production capacity, and technical expertise of the supplier as project-specific supplier selection criteria. They concluded that the proposed approach could successfully be used for selecting the most appropriate supplier.

Stević et al. [23] proposed a novel integrated multi-criteria model for supplier selection and integrated rough numbers with different MCDM methods in order to investigate subjective and unclear evaluation of the decision makers and to avoid the assumptions. In their study, they calculated the weights of the supplier selection criteria using both rough Decision Making Trial and Evaluation Laboratory (R'DEMATEL) and rough AHP (R'AHP), and ranked the supplier alternatives using rough MultiAttributive Ideal-Real Comparative Analysis (R'MAIRCA), rough MultiObjective Optimization by Ratio Analysis (R'MULTIMOORA), rough Complex Proportional Assessment (R'COPRAS), rough MultiAttributive Border Approximation area Comparison 
(R'MABAC), and rough Evaluation based on Distance from Average Solution (R'EDAS). They applied the proposed rough MCDM methods to a case study, identified 9 supplier selection criteria, namely quality of the material, price of the material, certification of the products, delivery time, reputation, volume discounts, warranty period, reliability, and the method of payments. They compared the ranking of the alternative suppliers obtained from different rough MCDM methods and conducted sensitivity analysis in order to see whether the ranking of the supplier alternatives is sensitive to the change in the criteria weights. They concluded that the proposed MCDM methods are applicable.

Tu et al. [4] proposed a multiobjective bilevel programming model for solving a supplier selection problem with multiple items (SSP-MI) in a largescale construction project using random fuzzy coefficients. The upper level of the model aims to deals with the contractors, who aim to select their suppliers to minimize total cost, maximize service and item quality, and the lower level of the model problem deals with the suppliers, who supply items to maximize their own total profit. In their study, 2 main supplier selection criteria, namely, service quality and item quality, and 4 sub-criteria under service quality (i.e., on-time delivery, response to changes, product development, financial \& organizational capability) and 3 sub-criteria under item quality (i.e., manufacturing capabilities, defects, total quality management), were determined. In order to test the effectiveness of the proposed approach, they applied it to the Pubugou Hydropower construction project The main contribution of this study is that it solves the supplier selection problem not only from the perspective of the contractors but also from the perspective of the suppliers.

Tamošaitienè et al. [24] proposed a hybrid MCDM approach for supplier selection. In the proposed approach, AHP was used to calculate the supplier selection criteria weights and the Additive Ratio Assessment Method (ARAS) and the Multiplicative Utility function was utilized for ranking and selecting candidate suppliers.
Moreover, the Hovanov method was used for normalizing the values of the criteria. They applied the proposed approach to a case study, namely a construction company that produce disposable containers in order to demonstrate how the proposed approach can be adopted in real life. They identified cost, quality, distance, and delivery, reliability, reputation, and technology level, compatibility and development ability as casespecific supplier selection criteria. They concluded that the proposed approach improved the reliability, consistency, and easiness to interpret the findings.

Seth et al. [25] proposed an AHP based MCDM framework in order to reveal the influence of competitive conditions on the construction supplier evaluation process. They identified 6 main supplier selection criteria, namely cost advantage or net price, quality competence, delivery ability, production facilities and location, management and organization, and performance history, and 3 subcriteria under quality competence (i.e., quality certifications, pricing proportionate, number of projects), 2 sub-criteria under delivery ability (i.e., lead time for initial quantity, production per month), 3 sub-criteria under management and organization (i.e., year of establishment, number of workmen, number of clients), 2 sub-criteria under performance history (i.e., number of projects, number of clients), and 2 sub-criteria under production facilities and location (i.e., production per month, location of factory/central warehouse). They mainly focused on large-scale housing project in order to demonstrate how the competitive capability and suppliers' profile affect the supplier evaluation process. They also applied the proposed framework to a case study and created various scenarios. The main contribution of their study was that they showed the impact of supply/market environment on the supplier evaluation, ranking.

Yazdani et al. [7] proposed an extended version of the combined compromise solution method with grey numbers (CoCoSo-G) for measuring the performance of suppliers in a construction company. They used two different methods, namely DEMATEL and Best Worst Method (BWM), for determining the importance levels of the supplier 
selection criteria. In the proposed approach, the DEMATEL method was used to identify the best and worst supplier selection criteria, the BWM method was used to sort the criteria based on a linear programming formulation, and the CoCoSo$\mathrm{G}$ method was used to rank the supplier alternatives according to the calculated scores. They applied the proposed methodolgy to a supplier selection problem in a construction company in Madrid called DOVHER Arquitectura. They identified 7 main supplier selection criteria, namely design, GHG pollution, delivery and flexibility, responsiveness and communication, financial condition, the offered price, and environmental management system, as company-specific supplier selection criteria. They also compared the results of the CoCoSo-G with those obtained by the COPRAS method and concluded that the CoCoSo-G can be successfully used for supplier selection in future studies.

Zhao et al. [26] proposed a method for supplier selection of a prefabrication project. The proposed method includes: listing the supplier selection criteria, providing adequate information about the project requirements and suppliers' profiles through Building Information Modelling (BIM), and ranking the importance levels of the supplier selection criteria and ranking the supplier alternatives using the AHP method. They took into account 5 main criteria, namely, financial strength, product performance, support services, quality system, and cost, and 4 sub-criteria under financial strength (i.e., fixed asset scale, cash flow conditions, credibility, financial conditions), 3 subcriteria under product performance (i.e., proper function, durability, appearance), 4 sub-criteria under support services (i.e., order processing, delivery on time, follow-up services, hazards handling mechanism), 4 sub-criteria under quality system (i.e., level of innovation, quality assurance, technical standards, complaint handling process), and 3 sub-criteria under cost (i.e., material cost, delivery cost, transaction cost). They applied the proposed method to a real prefabrication project and concluded that this method facilitated the supplier selection process as it provided adequate information in an effective way.

Zhang et al. [27] proposed a hybrid multi-expert MCDM model by integrating the BWM and CoCoSo methods based on interval rough numbers. They used the BWM method to find the supplier selection criteria weights and the CoCoSo method for ranking the alternative suppliers. The main novelty of this study is that they modified the BWM and CoCoSo methods with the probabilistic aggregation approach based on interval rough boundaries. In the proposed approach, decision makers express their individual evaluations on the criteria and the supplier performances using the Hesitant Fuzzy Linguistic Elements (HFLEs). HFLEs are more suitable in the case that decision makers do not have precise information in the qualitative evaluation process as they are closer to human cognition and perceptions. In order to aggregate different preferences of decision makers, Probabilistic Linguistic Terms (PLTs) based on interval rough number were used. They applied the proposed model to a property developer in China. They identified case-specific 5 main supplier selection criteria, namely quality, cost, green development, enterprise capability, and cooperation potentiality, and 3 sub-criteria under quality (i.e., product sample pass rate, level of after-sale service, product performance), 2 sub-criteria under cost (i.e., product price, installation cost), 2 sub-criteria under green development (i.e., environmental level, environmental effect), 3 sub-criteria under enterprise capability (i.e., innovation capability, professional skill, market position), and 2 subcriteria under cooperation potentiality (i.e., cooperation intention, supply capability of emergency demand). The main contribution of this study is that it effectively reflects different preferences of decision makers by handling the uncertainty and vagueness in the decision-making process.

Arıoglu et al. [28] introduced a supplier selection methodology, which segregates the impacts of different supplier features (i.e., product type and complexity, delivery characteristics and requirements, and geographic location of the 
project), for an organization that manages a large and complex construction project. Bayesian estimators were used to determine the model parameters that allows for information integration from previous periods. They applied the introduced methodology to the selection of raw materials suppliers for the production of tunnel construction concrete ring segments of the Eurasia Tunnel Project, and identified 4 main supplier selection criteria, namely product quality, on-time delivery, cost performance, and supplier reliability, and 4 sub-criteria under cost performance (i.e., adherence to payment schedule, adherence to delay interest terms, adherence to price increase terms, adherence to fixed price schedule) and 8 sub-criteria under supplier reliability (i.e., adherence to warranty terms, adherence to delay and penalty terms, meeting the claims for refund, work stoppage, references, quality assurance system, billing errors, manufacturing defects). They concluded that the introduced model provides decision makers with the rankings of the suppliers solely based on suppliers' own efforts.

\section{Findings and discussion}

The main findings of this study are summarized below:

- Supplier selection criteria are generally identified by the decision makers, who are experts and in charge of selecting the supplier to be worked with in the project or company in question. Only in limited number of the reviewed studies, the supplier selection criteria were identified in the light of the questionnaire survey.

- Cost, time and quality have been considered to be the primary criteria that significantly affect the supplier selection decision. This finding is very reasonable as they are the key success factors. The remaining criteria are specific to project/company/case in question.

- In early studies, environmental impact had not been considered in the supplier selection process. However, the environmental issues have been taken into account in recent studies as a result of the increasing awareness.
- In the large majority of the reviewed studies, the weights of the criteria and the ranking of the alternatives were calculated using different methods. AHP, DEMATEL and BWM are the most commonly used methods for determining the weights of the criteria, whereas varied MCDM techniques such as TOPSIS, ARAS, COPRAS, EDAS, CoCoSo, etc, can be used for ranking and selecting the alternative suppliers.

- In the early studies the simple version of the MCDM techniques had been used. However, in recent studies, the extended versions of the classic MCDM methods (i.e., fuzzy numbers, grey numbers, rough numbers, etc.) have been preferred as these versions better handle the uncertainty and vagueness in the decisionmaking process.

\section{Conclusions}

The cost of a construction work has three main components, which are labor, material, and equipment. Materials comprise approximately $40 \%$ of the overall project. Moreover, a construction project can be considered to be successful if it is completed within the estimated budget and duration, and meets the quality standards defined in specifications. Therefore, successful completion of a construction project is highly dependent on working with the right supplier for the right job. In the traditional approach, the suppliers, who offer the lowest price, are generally selected. However, the increasing competitiveness in the industry necessitates the employment of more robust and systematic approaches. Supplier selection process has attracted the researchers in the construction management field since the 1960s. Several studies, which either try to identify the supplier selection criteria and their importance levels or to propose MCDM techniques, have been carried out for solving the supplier selection problem. This study aimed to investigate how the studies, which focus on the supplier selection problem in the construction industry, evolved in terms of both the considered supplier selection criteria and the employed MCDM techniques over the past 10 
years. For his purpose, a semi-structured literature review was conducted.

It was found that nowadays contractors do not take into account only cost criterion when they select their suppliers. As the competition level increases and the projects become more complicated, different criteria such as delivery lead time, quality, technology capacity/R\&D ability, maintenance and spare parts service, environmental impacts, etc. have been considered by contractors as well as the price offered by the potential suppliers. Moreover, suppliers have been selected based on sound and analytical analyses rather than just project managers' subjective judgments. Construction practitioners can take into account the identified criteria and employ the appropriate technique for selecting the right supplier for their projects. This study is limited as it deals with supplier selection in construction projects. However, green supplier or sustainable supplier selection has gained importance recently with the increasing awareness of environmental issues. In future studies, green supplier or sustainable supplier selection practices in the construction industry can be investigated.

\section{Declaration of conflicting interests}

The author(s) declared no potential conflicts of interest with respect to the research, authorship, and/or publication of this article.

\section{References}

[1] Ibn-Homaid NT (2002) A comparative evaluation of construction and manufacturing materials management. International Journal of Project Management, 20(4): 263-270.

[2] Caldas C H, Torrent DG, Haas CT (2004). Integration of automated data collection technologies for real-time field materials management. 21st International Symposium on Automation and Robotics in Construction, 21-25 September 2004, Jeju, Korea.

[3] Cengiz AE, Aytekin O, Ozdemir I, Kusan H, Cabuk A (2017) A multi- criteria decision model for construction material supplier selection. Procedia Engineering, 196: 294-301.
[4] Tu Y, Zhou X, Gang J, Xu J, Shen W, Lev B (2017) Hierarchical supplier selection optimization with multiple items in large-scale construction projects. Journal of Infrastructure Systems, 23(3): 4017003.

[5] Benyoucef L, Ding H, Xie X (2003) Supplier selection problem: selection criteria and methods Research Report RR-4726, INRIA, 2003.

[6] Polat G, Eray E (2015) An integrated approach using AHP-ER to supplier selection in railway projects. Procedia Engineering, 123: 415-422.

[7] Yazdani M, Wen Z, Liao H, Banaitis A, Turskis Z (2019) A grey combined compromise solution (CoCoSo-G) method for supplier selection in construction management. Journal of Civil Engineering and Management, 25(8): 858-874.

[8] Chen W, Lei L, Wang Z, Teng M, Liu J (2018) Coordinating supplier selection and project scheduling in resource-constrained construction supply chains. International Journal of Production Research, 56(19): 6512-6526.

[9] Ho W, Xu X, Dey PK (2010) Multi-criteria decision-making approaches for supplier evaluation and selection: A literature review. European Journal of Operational Research, 202(1): 16-24.

[10] Patil AA, Kumthekar MB, Landage AB (2016) A review of supplier evaluation and selection approaches in supply chain of construction industry. International Journal of Engineering Research, 5(1): 120-122.

[11] Bygballe LE, Jahre M, Swärd A (2010) Partnering relationships in construction: A literature review. Journal of Purchasing and Supply Management, 16(4): 239-253.

[12] Bemelmans J, Voordijk H, Vos B (2012) Suppliercontractor collaboration in the construction industry: A taxonomic approach to the literature of the 2000-2009 decade. Engineering, Construction and Architectural Management, 19(4): 342-368.

[13] Aloini D, Dulmin R, Mininno V, Ponticelli S (2012) Supply chain management: a review of implementation risks in the construction industry. Business Process Management Journal, 18(5): 735761.

[14] Snyder H (2019) Literature review as a research methodology: An overview and guidelines. Journal of Business Research, 104: 333-339.

[15] Lam KC, Tao R, Lam MCK (2010) A material supplier selection model for property developers using fuzzy principal component analysis. Automation in Construction, 19(5): 608-618. 
[16] Zolfani SH, Chen I-S, Rezaeiniya N, Tamošaitienè J (2012) A hybrid MCDM model encompassing AHP and COPRAS-G methods for selecting company supplier in Iran. Technological and Economic Development of Economy, 18(3): 529543.

[17] Azambuja MM, O'Brien WJ (2012) Rapid assessment and selection of engineered equipment suppliers. Automation in Construction, 22: 587596.

[18] Eshtehardian E, Ghodousi P, Bejanpour A (2013) Using ANP and AHP for the supplier selection in the construction and civil engineering companies; Case study of Iranian company. KSCE Journal of Civil Engineering, 17(2): 262-270.

[19] Safa M, Shahi A, Haas CT, Hipel KW (2014) Supplier selection process in an integrated construction materials management model. Automation in Construction, 48: 64-73.

[20] Plebankiewicz E, Kubek D (2016) Multicriteria selection of the building material supplier using AHP and Fuzzy AHP. Journal of Construction Engineering and Management, 142(1): 4015057.

[21] Wang TK, Zhang Q, Chong HY, Wang X (2017) Integrated supplier selection framework in a resilient construction supply chain: An approach via analytic hierarchy process (AHP) and grey relational analysis (GRA). Sustainability, 9(2): 289.

[22] Polat G, Eray E, Bingol BN (2017) An integrated fuzzy MCGDM approach for supplier selection problem. Journal of Civil Engineering and Management, 23(7): 926-942.
[23] Stević Ž, Pamučar D, Vasiljević M, Stojić G,nKorica S (2017) Novel integrated multi-criteria model for supplier selection: Case study construction company. Symmetry, 9(11): 279.

[24] Tamošaitienè J, Zavadskas EK, Šileikaitė I, Turskis Z (2017) A novel hybrid MCDM approach for complicated supply chain management problems in construction. Procedia Engineering, 172: 11371145.

[25] Seth D, Nemani VK, Pokharel S, Al Sayed AY (2018) Impact of competitive conditions on supplier evaluation: a construction supply chain case study. Production Planning \& Control, 29(3): 217-235.

[26] Zhao L, Liu Z, Mbachu J (2019) Optimization of the supplier selection process in prefabrication using BIM. Buildings, 9(10): 222.

[27] Zhang Z, Liao H, Al-Barakati A, Zavadskas EK, Antuchevičienė J (2020). Supplier selection for housing development by an integrated method with interval rough boundaries. International Journal of Strategic Property Management, 24(4): 269-284.

[28] Arıoglu MÖ, Sarkis J, Dhavale DG (2021) Selection of suppliers using Bayesian estimators: a case of concrete ring suppliers to Eurasia Tunnel of Turkey. International Journal of Production Research, 59(18): 5678-5689. 